DOI: https://doi.org/10.24297/jssr.v14i0.7969

\title{
A Self-Assessment of a Philadelphia Group of Children, Youth and Family-Focused Agencies on Father Friendliness: A Descriptive Study
}

\author{
${ }^{1}$ Jeffrey Shears, ${ }^{2}$ Rufus Sylvester Lynch, ${ }^{3}$ Joshua Kirven \\ ${ }^{1}$ North Carolina A\&T State University and The University of North Carolina-Greensboro, \\ ${ }^{2}$ The Strong Families Commission Inc, ${ }^{3}$ Winthrop University
}

\begin{abstract}
This project explored the integration of Responsible Fatherhood within Foster Care Service within Philadelphia Pennsylvania. It was hypothesized that the key to reducing the number of children who are at risk of entering, re-entering and remaining in various systems of care are the social service programs and systems created to meet the needs of children. One element to improve the outcomes for children is to establish that engaging fathers of foster children can be important not only for the potential benefit of a child-father relationship but also for making placement decisions and gaining access to resources for the child. A diverse group of $n=22$ service providers voluntarily became involved in a multi-year participatory action research to explore the value of building capacity to integrate Responsible Fatherhood practices, programs, and/or initiatives within foster care service delivery and other children and youth servicing systems. The results from the study highlight a substantial distinction between baseline and post-evaluation of the agency's father readiness. The findings suggest that there were significantly higher scores on the father friendly checklist in the areas of leadership, polices \& procedures, staff development, parent programming, and fatherhood. The article summarizes key recommendation for social service agencies to develop initiatives that outreach to fathers not only to connect with their children, but to build a broader support network that enhances child safety, permanency and wellbeing.
\end{abstract}

Keywords: Fathering, Social Service Agencies, Adoption

\section{Introduction}

Most children are raised by their biological parents in a healthy, supportive environment, and rarely experience a disruption of their parents' emotional, social, physical, intellectual, spiritual or financial support. In 2016 the U.S. Census Bureau reported that the $69 \%$ of Americans under the age of 18 live in families with two parents. Children living with their mother only made up the second-most common family structure at 23 percent. The percent living only with their father represented 4 percent, and children not living with a parent equaled 4 percent as well (Census.gov, 2017).

Pennsylvania's figures reflect the national figures in that $35 \%$ of children reside in a single parent family household; while Philadelphia has a higher rate of children living in single family households at about 59\% percent (Kids Count, 2017).

In addition to children residing with their biological parents, the Children's Rights Organization - defending America's abused and neglected kids (Children Rights, 2016), report that there are nearly 428,000 children on any given day in the foster care system in the United States, with over 670,000 in 2015 who spent some time in foster care. For many of these children the average amount of time spent in state care is about two years, but for many children in foster care they can languish in family home care, group homes or institutional care for five or more years.

The National Fatherhood Initiative (NFI), one of the leading organizations advocating for fathers reports that children in father absent homes are at greater risk of poverty; seven times more likely to experience teen 
pregnancy; twice as likely to suffer obesity, drop out of school and are at greater risk of infant mortality; more likely to have behavior problems, face child abuse and neglect, as well as abuse drugs; further they are more likely to commit a crime and go to prison (National Fatherhood Initiative, 2017).

A senior fellow at the Stoneleigh Foundation in Philadelphia, Pennsylvania with a project to explore the integration of Responsible Fatherhood within Foster Care Service Delivery and other children and youth servicing systems hypothesized the key to reducing the number of children who are at risk of entering, entering, reentering and remaining in various systems of care are the social service programs and systems created to meet the needs of our most vulnerable child population (Stoneleigh Foundation, 2018). We believe that the child welfare system is not and never was designed or organized to maximize fathers' contribution to their children's happiness, comfort, security or general welfare.

Consequently, these systems of care are typically not including fathers as resources essential to ensuring the safety, permanency, and well-being of children. Even more challenging is the fact that child welfare history reflects an on-going emphasis on serving mothers, notwithstanding social science research increasingly highlighting the important role of fathers in children's development.

Current policy regarding child protection services places increasing demands for providers to engage fathers whose children are involved in the child protection process. Implementation of this policy clashes with the ongoing challenges that fathers have historically faced in working within these systems (Gordon et al., 2012).

The result of these historical policies and procedures that have failed to maximize father involvement by focusing on mothers, often result in children not being fully served. This article will examine the effectiveness of an intervention to build agency capacity to include fathers in their service delivery models by examining and assessing leadership and organizational philosophy at the Board of Directors, CEO, and Senior Administrative levels within the organization; program management as reflected in agency policies, practices, procedures and protocols; program development and enhancement; staff internal development as well as external professional achievement; program physical environment; parent programming and education initiatives; responsible fatherhood programming; community outreach, collaboration, and organizational networking; and the hiring, training and Integrating males within their service delivery models.

\section{The Father-Agency Disconnect:}

Numerous studies have highlighted fathers' often difficult interactions with health and social services and their low satisfaction with those services (Deave \& Johnson, 2008; Gervais et al., 2016; Premberg, Hellström, \& Berg, 2008). Now that these experiences and interactions are being documented, it is time to move from description to intervention and build on this evidence to develop programs to support fathers (Metz \& Bartley, 2012).

However, many children, youth and family-focused systems of care appear to be quite resistant to fatherinclusive practice. More specifically the lack of attention to fathers in child welfare services has been welldocumented in general social work literature nationally as well as internationally and, according to some, ignoring fathers is deeply embedded in child welfare practice (Brown et al, 2009; Do Minelli et al., 2011; Strega et al., 2009). Maxwell et al. (2012) posits that there is an assumption that men are not the "core business" of child protection workers given the fact that women are the primary caretakers of children of single parent households.

Others claim there is a pervasive negative stereotype of fathers and father figures in child welfare families and that, as a result, they are treated with suspicion and assumed to be absent, unimportant, dangerous and generally 'bad' (Bellamy, 2009; Coady, Hoy \& Cameron, 2013). These negative perceptions may lead to a lack of engagement by workers and a tendency to exclude fathers from at-risk children's lives. Therefore, despite the fact that in the wider public arena father involvement is being encouraged, child welfare practices, procedures and protocols tend to promote uninvolved, rather than involved, fathering (Brown et al., 2009). 
In practice, including fathers can be very challenging due to factors such as the complexities of modern family composition, mothers not wanting fathers involved, avoidance and resistance from fathers themselves, and the fear of domestic violence felt by Mom or Dad and perhaps even the children within the family. Therefore, since there are reasonable explanations to avoid fathers in serving families, a very convincing argument is required to justify altering current practice and expending scarce resources to engage and study fathers (Zanoni et al., 2013).

The importance of including fathers in child welfare services is increasingly reflecting that it should be required in the child's case plan instead of an option (Chawla \& Milner, 2016; Coakley, Shears, \& Randolph, 2014). Fathers have a narrative and perspective to contribute, not to only validate their role but enrich their children's lives (Kirven, 2014). Such inclusion will strengthen the case plan and contributes to the well-being and development of children who are entered, at risk of entering or remaining in foster care. In addition, reaching out to fathers encourages them to meet their family obligations; strengthen their ties to the community, reaffirms their purposes and helps establish a more favorable relationship with the mother (Zanoni et al, 2013).

Seeking assistance from a child welfare social service agency may be particularly difficult for men. The difficulty maybe more pronounced when fathers seek to reengage with their children but are met with hostility or judgement. This lack of connection between child welfare and fathers suggest a scarcity of knowledge about what kinds of interventions are most appropriate in working and advocating for fathers. One area that might increase the effective interaction between fathers and child welfare is based on Resilience theory.

Zimmerman (2013) purports resiliency as the ability of overcoming the negative effects of risk, coping effectively with traumatic experiences, and avoiding the negative trajectories through a strengths-based approach. In other words, Resiliency is the ability to cope and progress from challenging and difficult experiences such as being detached from your children. Resilience theory supports the mindset of focusing on strengths and what is important leading to a more positive level of functioning (Marsiglia \& Kulis, 2009).

Whether it is perceived and/or factual, this experience can have an initial damaging impact on fathers' efforts and commitment to take the necessary steps to be in their child's life. Social services and male-supportive resources can be a connector for agencies in reaching fathers (Scourfield, Cheung, \& MacDonald, 2014). Lack of resiliency is often an ongoing trait for fathers who are not with their children. The capacity to look at the strengths of fatherhood when faced with specific risks and discrimination causes them use protective factors as they are needed (Zimmerman \& Brenner, 2010).

How can these agencies reflect a welcoming place of "father friendliness" when fathers first walk through the door? This interaction after fathers decide to make that first step is pivotal in exhibiting a "safe place and space" for them to feel invited, otherwise they may not come back (Malm \& Zielewski, 2009). Relevant studies have counteracted the perception that all men are unengaged and absent from their families in the child welfare system (Bellamy, 2009; Coady, Hoy \& Cameron, 2013; Malm \& Zielewski, 2009; Strega et al, 2009).

Occasionally, when service providers come together to discuss the engagement of fathers or their attempts to get fathers involved in family briefings, case planning and supervisory meetings, a common theme that they may hear from disempowered fathers is "I am not where I want to be right now but recognize the importance and urgency of being in my child's life." (Baum, 2017; Coady, Hoy \& Cameron, 2013). What happens next is key.

Reasons why social service agencies may be unsuccessful in keeping fathers interested and engaged can be: 1) services are tailored to mothers because they are often thought to be the main caregiver (Dollahite, 2004; Towers, 2007; Turbiville \& Marquis, 2001), 2) female staff members may not feel comfortable working with fathers (Turbiville \& Marquis, 2001; Metz \& Bartley, 2012), 3) staff members may not know how to work with fathers (Carpenter \& Towers, 2008; Zanoni et al., 2013), and 4) agency philosophy, policies, practices, procedures, and protocols don't reflect the value of father inclusion in their service delivery models, as advocated by The Strong Families Commission, Incorporated (THE COMMISSION) agency accreditation process (The Strong Families Commission, 2018). 
Given that research shows that fathers not only have the capacity for care giving, but that children benefit directly from dad's parenting contributions, agencies need to commit more resources and focus on the unique needs of serving fathers within their service delivery models. (Do Minelli et al., 2011; Gervais, et al., 2016; Metz \& Bartley, 2012).

\section{The Intervention}

The Philadelphia Department of Human Services (DHS), and their contracted child and family service providers historically faced similar challenges of engaging fathers as an integral part of their service to children and families. Moreover, their well-known practice modality, when parent unification was not immediate, was centered in kinship family care placement, which typically was limited to a female grandmother, aunt, or cousin or maternal family members. This practice does not take into consideration an often cited Federal 2006 Report titled "What about the Dads?" which established that engaging fathers of foster children can be important not only for the potential benefit of a child-father relationship (when such a relationship does not pose a risk to the child's safety or well-being), but also for making placement decisions and gaining access to resources for the child. More specifically, this report suggests that engaging the paternal side of the family may increase the potential resources for the child.

In that regard, a diverse group of Philadelphia children, youth and family service providers voluntarily became involved in a multi-year participatory action research initiative with a Senior Fellow from the Stoneleigh Foundation to explore the value of building capacity to integrate Responsible Fatherhood practices, programs, and/or initiatives within foster care service delivery and other children and youth servicing systems. The Stoneleigh Foundation is a Philadelphia based organization founded in 2006 by John and Chari Haas to improve the life outcomes for Philadelphia's most vulnerable youth. It meets its mission by awarding Fellowships to exceptional leading practitioners, researchers, and policymakers who work within and alongside youth-serving systems (child welfare, juvenile justice, education and health) to catalyze change (Stoneleigh Foundation, 2018). Fundamental goals of the Foundation are to 1) nurture new approaches and ideas that lead to widespread policy and practice change, 2) change how public and private systems work together to meet the needs of the whole child, 3) develop new knowledge through research and its translation to policy and practice, and 4) support individuals and a community of fellows who can make a difference in the lives of vulnerable children.

The Senior Fellow project, which partnered with the Graduate School of Social Work and Social Research (GSSWSR) at Bryn Mawr College, sought to encourage change in agency organizational practice, as well as recognition and inclusion of fathers in services to the families they served. GSSWSR has long believed the delivery of social services by agencies in the public and private sectors must respond to what at times seem to be overwhelming needs and demands from those who pay for and use the services, as well as from those who ultimately establish the policies on which funding is based. It maintains its commitment to strengthening public and private agencies by working collaboratively with them to plan, administer, provide, and evaluate services that can have a positive and lasting impact on individuals, families and communities. GSSWSR is committed to educating social workers who are excited by the challenges this nation faces and determined to help bring about the social changes that have been needed for far too long (Bryn Mawr College Graduate School of Social Work and Social Research, 2018).

\section{Agency Capacity Building as a Solution}

Through agency assessment of philosophy, policy, practice, procedure and protocol, by agency management and staff, the project goal was to measure the readiness of a select group of agencies to enhance their service delivery to Philadelphia's children and youth, by acknowledging and including fathers as an important factor to consider when contemplating the well-being of children. The participant agencies' objective was the expansion of their capacity to involve fathers in the lives of their children as a fundamental element of their social delivery models, and to establish a collaborative community with other agencies seeking to involve more father participation within service delivery. 
The capacity building support offered to participating agencies included: 1) assessment of their agency's "Father Friendliness," as viewed by management and staff; 2 ) individual consultation regarding steps toward identifying their agency capacity building initiative; 3) technical assistance in the development of Responsible Fatherhood programming (new or enhanced); 4) an opportunity to engage in specialized focus groups (for management, staff, youth aging out of foster care, single mothers, and single fathers) designed to identify system impediments that contribute to the lack of Father Involvement in the lives of children; 5) an individual agency retooling plan that spells out what is needed to move the agency forward in the areas of Father Friendliness and inclusiveness; 6) the advantage of an association with a nationally recognized subject matter expert as a pro bono resource for future Fatherhood funding; and 7) potential accreditation as a Father Friendly Flagship Agency (3FA) that utilizes enriched family philosophy, policies, practices, procedures, and protocols to improve child well-being.

\section{Project definition of Responsible Fatherhood and Program Guided Principles}

Project definition of Responsible Fatherhood, taken from many sources and conversations

integrated into seven essential elements:

- $\quad$ Reduce the chances of un-partnered fertility;

- Establish and Own paternity, when in doubt testing is encouraged;

- Engage early on (prenatal) in collaborative parenting with the child's mother;

- Whether married, single, co-habituating, or living a part, Father needs to negotiate his role and function as Dad with Mom or child's legal guardian or caretaker;

- Be an on-going responsible adult source for emotional, social, physical, intellectual, spiritual, and financial care giving;

- Maintain an active presence in the child's span of life; and

- Be willing to collaboratively work with members of the child's family, to achieve economic stability and wealth acquisition in order to provide for the child's financial future needs over time.

\section{Principles to Remember:}

- $\quad$ Fathers can be important contributors to the well-being of their children;

- Parents are partners in raising their children, even when they do not live in the same household;

- The role Fathers play in families are diverse and related to cultural and community norms;

- Men should receive the education and support necessary to prepare them for the responsibility of parenthood; and

- The supporting role of Individuals from the Private, Public, Corporate, Business, Philanthropic, and the Community at-large is to encourage and promote Father involvement through Father Friendly policies and programs that support strengthening families to ensure the well-being of children.

\section{Self-Assessment as the Beginning Process}

In moving towards a more sensitive method for building capacity to include fathers' in the lives of children and families the following approach is introduced using the Father Friendly Flagship Agency (3FA) prototype. 


\section{FA Participatory Action Research Approach}

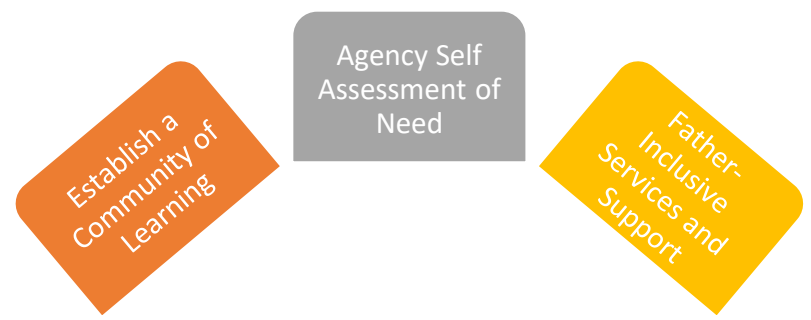

Agency Self-Assessment activities can be a starting point in gauging child welfare agencies' interest and tolerance to examine more productive ways to involve fathers in service delivery to children and families. Such agencies through self-assessment, training and piloted programming can develop the sensitivity and skills needed to interact with fathers which in turn can support Father-child relationships.

Sample

The participants in this study consisted of $n=22$ non-profit agencies in the greater Philadelphia area that reported offering a variety of services to families. The sample of participants within the agencies was categorized into staff $(n=366)$ or managers $(n=62)$. The participants indicated which role they served at their agency. Those who reported being staff also indicated they were program clerical/technical staff $n=74$ (20.3\%), program line staff $n=215$ (58.7\%), and program supervisor $n=77$ (21.0\%). The managers reported being board members $n=3$ (2.8\%) CEO or Designee $n=16(25.8 \%)$, program director $n=39(62.9 \%)$ or another managerial staff $n=4(6.5 \%)$. This provided a fairly representative sample of the numerous types of decision makers, front line staff to board members, all with the opportunity to influence policy and work directly with fathers.

Survey

The study utilized the IAWF Father Friendly Flagship Agency Check-Up Tool (IAWF 3FA Check-Up Tool) which is a 5-point Likert scale with ten sub-domains. These sub-domains include Leadership and Organizational Philosophy at and below the Board of Directors and CEO level; Program Management as reflected in policies, procedures and protocols; Program Development and Enhancement; Staff Development and Professional Development; Program Physical Environment; Parent Education Programming; Father Identification and Engagement Agenda; Community Outreach, Collaboration, and Organizational Networking; and Hiring, Training, and Integrating Males within Service Delivery. The research design (R13-034 "The integration of responsible fatherhood within foster care delivery and other systems of care) and survey instrument (IAWF 3FA Check-Up Tool) were approved by the Institutional Review Board (IRB) at Bryn Mawr College.

\section{Descriptive Results at Baseline}

\begin{tabular}{|l|l|l|l|}
\hline Agency & Range & Mean & $\begin{array}{l}\text { Standard } \\
\text { Deviation }\end{array}$ \\
\hline The Board Leadership \& CEO of my organization N=361 & $1-5$ & 4.17 & .849 \\
\hline Leadership \& Organizational Philosophy N=338 & $1-5$ & 3.49 & .860 \\
\hline Policies and Procedures N=306 & $1-5$ & 3.84 & .890 \\
\hline Program development \& enhancement N=299 & $1-5$ & 3.79 & .841 \\
\hline
\end{tabular}




\begin{tabular}{|l|l|l|l|}
\hline Staff development \& professional development N=291 & $1-5$ & 3.49 & .971 \\
\hline Program physical environment N=297 & $1-5$ & 3.48 & .887 \\
\hline Parent Program Programming N=275 & $1-5$ & 3.60 & .932 \\
\hline Responsible Fatherhood N=261 & $1-5$ & 3.56 & .921 \\
\hline Community Outreach, Collaboration, \& Organization Networking N=267 & $1-5$ & 3.45 & .933 \\
\hline Hiring, Training, \& Integrating Males within Service Delivery N=272 & $1-5$ & 3.80 & .804 \\
\hline
\end{tabular}

Table 1 - Combined Staff and Managers Baseline Descriptive results - Time 1

The descriptive results at baseline indicate that both staff and managers rated their agency high on all the standard domains with the rating of Board Leadership \& CEO of my organization receiving the highest rating at $\mathrm{M}=4.17$ and Community Outreach, Collaboration, \& Organization Networking receiving the lowest ranking at 3.45. Nevertheless, it appears that the combine staff and managers had a relatively strong perception of their agency being father-friendly in their approach with working with fathers. Notwithstanding that none of the agencies used the terms father, fathering or fatherhood in their mission or vision statement.

\section{Bivariate Analysis at Base Line Between Managers and Staff}

The results suggest that there were significant differences between staff and managers' report on the IAWF 3FA Check-Up Tool at baseline. There was a significant difference in Leadership and Organizational Philosophy with Staff $(M=3.57, S D=.865)$ and Managers $(M=3.11, S D=.730) t(-3.63)=p<.001)$, policies and procedures Staff $(M=3.89, S D=.863)$ and Managers $(M=3.57, S D=.991) t(-2.35)=p<.05)$, program development \& enhancement Staff $(M=3.85, S D=.832)$ and Managers $(M=3.49, S D=.840) t(-2.66)=p<.01)$, responsible fathering Staff $(M=3.62$, $\mathrm{SD}=.935)$ and Managers $(\mathrm{M}=3.23, \mathrm{SD}=.780) \mathrm{t}(-2.65)=\mathrm{p}<.01)$. And Community Outreach, Collaboration and Organizational Networking Staff $(M=3.40, S D=.842)$ and Managers $(M=2.96, S D=.665) t(-3.35)=p<.001)$. There were not significant differences in other areas between staff and managers. This suggest that staff and managers viewed some of the standard domains differently. When there were statistical differences between the staff and managers reports, staff tended to have a higher score than managers, or a more favorable opinion.

Table 2 - Combined Staff and Managers Post Descriptive Results - Time 2

\begin{tabular}{|l|l|l|l|}
\hline Agency & Range & Mean & $\begin{array}{l}\text { Standard } \\
\text { Deviation }\end{array}$ \\
\hline The Board Leadership \& CEO of my organization N=207 & $1-5$ & 4.27 & .662 \\
\hline Leadership \& Organizational Philosophy N=201 & $1-5$ & 3.00 & .799 \\
\hline Policies and Procedures N=186 & $1-5$ & 4.01 & .746 \\
\hline Program development \& enhancement N=177 & $1-5$ & 3.93 & .756 \\
\hline Staff development \& professional development N=170 & $1-5$ & 3.70 & .853 \\
\hline Program physical environment N=165 & $1-5$ & 3.54 & .831 \\
\hline
\end{tabular}




\begin{tabular}{|l|l|l|l|}
\hline Parent Program Programming N=166 & $1-5$ & 3.81 & .890 \\
\hline Responsible Fatherhood N=159 & $1-5$ & 3.84 & .859 \\
\hline $\begin{array}{l}\text { Community Outreach, Collaboration, \& Organization Networking N = } \\
158\end{array}$ & $1-5$ & 3.63 & .892 \\
\hline Hiring, Training, \& Integrating Males within Service Delivery N=155 & $1-5$ & 3.94 & .840 \\
\hline
\end{tabular}

Given the baseline report, the descriptive post intervention results indicate that both staff and managers continued to rate their agency high on all the standard domains with the rating of Board Leadership \& CEO of my organization remaining the highest at $M=4.27$ and Leadership \& Organizational Philosophy receiving the lowest ranking at $\mathrm{M}=3.00$.

\section{Bivariate Results}

The results indicate that there were significant differences between baseline and post evaluation of father readiness. Table 2 indicates that the programs reported significantly higher scores on the IAWF 3FA Check-Up Tool in the areas of Leadership, Polices \& Procedures, Staff Development, Parent Programming, \& Fatherhood. Surprisingly, the significant change in Leadership \& Organizational Philosophy actually decreased from baseline to post intervention. It should be noted that some other areas suggested change in scores over time but were not statistically significant. These included Community outreach $p=.056$, hiring, training, \& integrating males $\mathrm{p}=.075 \&$ program development $\mathrm{p}=.067$.

Table 3-Agency Functions Stratification

\begin{tabular}{|c|c|c|c|c|c|c|c|c|}
\hline & $M$ & SD & $\mathrm{n}$ & $\mathrm{M}$ & SD & $\mathrm{n}$ & $\mathrm{t}$ & Df \\
\hline Board Leadership & 4.17 & .849 & 361 & 4.27 & .662 & 207 & -1.58 & 566 \\
\hline $\begin{array}{l}\text { Leadership \& Organizational } \\
\text { Philosophy }\end{array}$ & 3.49 & .860 & 338 & 3.00 & .799 & 201 & $-2.80 *$ & 537 \\
\hline Policies \& Procedures & 3.84 & .890 & 306 & 4.01 & .746 & 186 & -2.18 & 490 \\
\hline $\begin{array}{l}\text { Program Development \& } \\
\text { Enhancement }\end{array}$ & 3.79 & .890 & 306 & 3.93 & .756 & 177 & -1.83 & 474 \\
\hline Staff Development & 3.49 & .971 & 291 & 3.70 & .853 & 170 & $-2.37^{*}$ & 459 \\
\hline Physical Environment & 3.48 & .887 & 297 & 3.54 & .831 & 165 & -.680 & 460 \\
\hline Parent Program & 3.60 & .921 & 261 & 3.81 & .890 & 166 & $-2.30^{*}$ & 439 \\
\hline Responsible Fatherhood & 3.56 & .921 & 261 & 3.84 & .859 & 159 & $-3.02^{*}$ & 418 \\
\hline Community Outreach & 3.45 & .933 & 267 & 3.63 & .892 & 158 & -1.91 & 423 \\
\hline $\begin{array}{l}\text { Hiring, Training \& } \\
\text { males }\end{array}$ & 3.80 & .804 & 272 & 3.94 & .840 & 155 & -1.78 & 425 \\
\hline
\end{tabular}


$\mathrm{p}<.05$

\section{Discussion \& Implications}

Personnel within social service agencies, including board members, may reflect a cognitive disconnect between management and front-line workers, regarding agency willingness to including fathers in services to children and families. It is important to show consistency of service-delivery philosophy from agency administration to the direct-practice staff. There should be a feeling of warmth and value that is dispelled when fathers show up at the social service agency. This welcoming, inclusive work environment can reflect an agency that is willing to engage fathers with supportive services and resources that can enhance the well-being of the child as well as his or her caretaker.

The results from the study shows a disparity at baseline between direct staff and managers highlighting that there were substantial distinctions between baseline and post-evaluation of the agency's father readiness. The findings suggest that there were significantly higher scores on the father friendly checklist in the areas of leadership, polices \& procedures, staff development, parent programming, and fatherhood.

The results from the study are also favorable that the perceived differences between staff and management were no longer present at post intervention. Additionally, there was significant difference in baseline and post in the agency perception of their agency being father friendly. The difference in staff and management was significant at baseline with the staff indicating a higher rating of agency being father friendly than did the managers. The results of this study suggest that much of the change in the participants' perception of being father friendly were with the managers.

Social service agencies may often have the intent of engaging fathers in the needs of their children but fall short in offering favorable incentives, services and system referrals that attract fathers. Literature that looks at how social service programs include fathers is sparse, and research looking within the operations of these agencies is even worst. This study is one of the first of its kind in looking at how to get social service agencies to be more friendly and connected to fathers who want to have an active role in the lives of their children.

Potential services and programs that show promise are support circles and empowerment workshops in agency buildings, barbershops, and proud dad "Speak out Sessions" (SOS). "Father Friendly" social services literature can be a starting point in gauging fathers' interest desire to get and stay involved while looking at themselves as part of the solution instead part of the problem. Agencies who have the sensitivity and skill in assisting fathers in keeping focus on what's important can strengthen their self-worth, purpose and identity as a proud father in maintaining engagement.

The conundrum is that social service programs and systems dedicated to meeting the needs of children are not, and never were, designed or organized, to maximize fathers' contributions to their children's well-being. Consequently, these systems of care are typically not including fathers as resources essential to ensuring the safety, permanency, and well-being of children. Even more challenging is the fact that child welfare history reflects an on-going emphasis on serving mothers, notwithstanding social science research increasingly highlighting the important role of fathers in children's development.

A key recommendation for social service agencies moving forward can be to develop initiatives that outreach to fathers not only to connect with their children, but to build a broader support network that enhances child safety, permanency and well-being.

Although many community resources are ill-prepared to deal with deeper social problems, like long-term poverty, agencies can still serve as an asset in engaging fathering in community building. But even if that's beyond their capacity, agencies can still keep men engaged with their children through program activities like sports, arts and tutoring and help them establish individual benchmarks of pursuing employment, furthering training or education, effective parenting and positive relationship with mother of child. Also, agency staff 
identifying fathers who are willing to serve as peer mentors can build goodwill and trust for agencies. Because some men tend to look to other men rather than women for approval, it makes sense to create opportunities that increase the chances for fathers to associate in meaningful ways with other fathers. When other men make it clear that being a nurturing, engaged dad is expected, fathers tend to listen.

Social service agencies can prove to be father-friendly and inclusive of fathers if they are willing to assess and change, where necessary, their philosophy, policies, practices, procedures, and protocols that will better attract and more support men to become greater contributors to their child and family well-being.

\section{References}

1. Allen, Q. (2016). 'Tell your own story': manhood, masculinity and racial socialization among black fathers and their sons. Ethnic and Racial Studies, 39(10), 1831-1848.

2. Baum, N. (2017). Gender-sensitive intervention to improve work with fathers in child welfare services. Child \& Family Social Work, 22(1), 419-427. doi:10.1111/cfs.12259

3. Bellamy, J.L. (2009). A national study of male involvement among families in contact with the child welfare system. Child Maltreatment, 14 (3), 255-262.

4. Brown, L., Callahan, M., Strega, S., Walmsley, C., \& Do Minelli, L. (2009). Manufacturing ghost fathers: The paradox of father presence and absence in child welfare. Child \& Family Social Work, 14(1), 25-34.

5. Bryn Mawr. (2018). Bryn Mawr College Graduate School of Social Work and Social Research. Retrieved from https://www.brynmawr.edu/socialwork/

6. Carpenter, B., \& Towers, C. (2008). Recognizing fathers: The needs of fathers of children with disabilities. Support for Learning, 23(3), 118-125.

7. Chawla-Duggan, R., \& Milner, S. (2016). Father involvement in young children's care and education: exploring boundaries and starting conversations. Cambridge Journal of Education, 46(4), 473-489.

8. Children's Rights. (2016). Foster care fact sheet. Retrieved from http://www.childrensrights.org/newsroom/fact-sheets/foster-care/

9. Coakley, T. M., Shears, J. K., \& Randolph, S. D. (2014). Understanding Key Barriers to Fathers' Involvement in Their Children's Lives. Child \& Youth Services, 35(4), 343-364.

10. Coady, N., Hoy, S., \& Cameron, G. (2013). Fathers' experiences with child welfare services. Child \& Family Social Work, 18(3), 275-284. doi:10.1111/j.1365-2206.2012. 00842.x

11. Crenshaw, K. (1995). Critical race theory: The key writings that formed the movement. The New Press.

12. Deave, T., \& Johnson, D. (2008). The transition to parenthood: what does it mean for fathers? Journal of advanced nursing, 63(6), 626-633.

13. Dollahite, D. C. (2004). A narrative approach to exploring responsible involvement of fathers and their special-needs children. In R. D. Day, M. E. Lamb (Eds.), Conceptualizing and measuring father involvement (p. 109-127). Mahwah, NJ: Lawrence Erlbaum Associates Publishers.

14. Do Minelli, L., Strega, S., Walmsley, C., Callahan, M., \& Brown, L. (2010). 'Here's my story': Fathers of 'looked after 'children recount their experiences in the Canadian child welfare system. The British Journal of Social Work, 41(2), 351-367. 
15. David Hansell, Principal Deputy Assistant Secretary, Administration for Children and Families (ACF), U.S. Department of Health and Human Services (HHS), April 19, 2011. Opening Remarks before the Committee on Ways and Means, Subcommittee on Income. U.S. House of Representatives.

16. Gervais, C., de Montigny, F., Lacharité, C., \& Dubeau, D. (2015). The Father Friendly Initiative within Families: Using a logic model to develop program theory for a father support program. Evaluation and program planning, 52, 133-141.

17. Gervais, C., de Montigny, F., Lacharité, C., \& St-Arneault, K. (2016). Where fathers fit in Quebec's perinatal health care services system and what they need. Psychology of Men \& Masculinity, 17(2), 126.

18. Gordon, D. M., Oliveros, A., Hawes, S. W., Iwamoto, D. K., \& Rayford, B. S. (2012). Engaging fathers in child protection services: A review of factors and strategies across ecological systems. Children and youth services review, 34(8), 1399-1417.

19. Kids Count (2017). Kids Count data center - A Project of the Annie E. Casey Foundation. Retrieved from http://datacenter.kidscount.org/

20. Kirven, J. (2014). The reality and responsibility of pregnancy provides a new meaning to life for teenage fathers. International Journal of Choice Theory and Reality Therapy, 2, 23-28.

21. Malm, K.E. \& Zielewski, E.H. (2009) Nonresident father support and reunification outcomes for children in foster care. Children and Youth Services Review, 31, 1010-1018.

22. Marsiglia, F. F., \& Kulis, S. S. (2009). Diversity, oppression, and change: Culturally grounded social work. Chicago, IL: Lyceum Books.

23. Maxwell, N., Scourfield, J., Holland, S., Featherstone, B. and Lee, J. (2012). The benefits and challenges of training child protection social workers in father engagement. Child Abuse Review, 21(4) 299-310. doi:10.1002/car.2218

24. Metz, A., \& Bartley, L. (2012). Active Implementation Frameworks for Program Success: How to Use Implementation Science to Improve Outcomes for Children. Zero to Three (J), 32(4), 11-18.

25. National Fatherhood Initiative. (2016). Understanding dad: An awareness and communications program for moms. Germantown, MD. Retrieved from www.fatherhood.org/free-resource/topic/understandingdad.

26. Premberg, Å., Hellström, A. L., \& Berg, M. (2008). Experiences of the first year as father. Scandinavian journal of caring sciences, 22(1), 56-63.

27. Scourfield, J., Cheung, S. Y., \& Macdonald, G. (2014). Working with fathers to improve children's wellbeing: Results of a survey exploring service provision and intervention approach in the UK. Children and Youth Services Review, 43, 40-50.

28. Stoneleigh Foundation. (2018). Child Welfare. Retrieved from https://stoneleighfoundation.org/ourpriorities/child-welfare/

29. Strega, S., Brown, L., Callahan, M., Do Minelli, L. \& Walmsley, C. (2009). Working with me, working at me: fathers' narratives of child welfare. Journal of Progressive Human Services, 20(1), 72-91.

30. The Majority of Children Live with Two Parents. U.S. Census Report \# CB 16-192, Released November 17, 2016. 
31. The Integration of Responsible Fatherhood within Foster Care Service Delivery, Application Project Proposal. December 22, 2011.

32. The Strong Families Commission. (2018). Mission Statement. Retrieved from https://www.thestrongfamiliescommission.com/

33. Towers, C. (2007). Let's not forget about fathers. Learning Disability Today, 7(2), 15-19.

34. Turbiville, V. P. \& Marquis, J. G. (2001). Father participation in early education programs. Topics in Early Childhood Special Education, 21(4), 223-231.

35. U.S. Census Bureau. (2017). Historical living arrangements of children [Table $\mathrm{CH}$-1]. Retrieved from https://www. census.gov/data/tables/time-series/demo/families/ children.html

36. Zanoni, L., Warburton, W., Bussey, K., \& McVaugh, A. (2013). Fathers as 'core business' in child welfare practice and research: An interdisciplinary review. Children and Youth Services Review, 35(7), 1055-1070.

37. Zimmerman, M. A., Stoddard, S. A., Eisman, A. B., Caldwell, C. H., Aiyer, S. M., \& Miller, A. (2013). Adolescent Resilience: Promotive Factors That Inform Prevention. Child Development Perspectives, 7(4), 10.1111/cdep.12042.http://doi.org/10.1111/cdep.12042

38. Zimmerman M. A., Brenner A. B. (2010). Resilience in adolescence: Overcoming neighborhood disadvantage. In Reich J. W., Zautra A. J., Hall J. S. (Eds.), Handbook of resilience. New York: Guilford Press. Pp. 283-308. 